\title{
Recovery of Cobalt from the Residues of an Industrial Zinc Refinery
}

\author{
Laurence Boisvert ${ }^{1}$, Keven Turgeon ${ }^{1}$, Jean-François Boulanger ${ }^{2}{ }^{\oplus}$, Claude Bazin $^{1, *}$ and \\ Georges Houlachi ${ }^{3}$
}

1 Department of Mining, Metallurgical and Materials Engineering, Université Laval, Québec, QC G1V 0A6, Canada; laurence.boisvert.1@ulaval.ca (L.B.); keven.turgeon.1@ulaval.ca (K.T.)

2 Institut de Recherche sur les Mines et l'Environnement, Université du Québec en Abitibi Témiscamingue (UQAT), Rouyn-Noranda, QC J9X 5E4, Canada; Jean-Francois.Boulanger@uqat.ca

3 Institut de Recherche, Hydro-Québec, Varennes, QC J3X 1S1, Canada; houlachi.georges@hydroquebec.com

* Correspondence: claude.bazin@gmn.ulaval.ca; Tel.: +1-418-656-5914

Received: 4 November 2020; Accepted: 19 November 2020; Published: 22 November 2020

check for updates

\begin{abstract}
The electrolytic production of metallic zinc from processing zinc sulfide concentrates generates a residue containing cadmium, copper, and cobalt that need to be removed from the electrolytic zinc solution because they are harmful to the zinc electro-winning process. This residue is commonly sent to other parties that partly recover the contained elements. These elements can generate revenues if recovered at the zinc plant site. A series of laboratory tests were conducted to evaluate a method to process a zinc plant residue with the objective of recovering cobalt into a salable product. The proposed process comprises washing, selective leaching, purifying and precipitation of cobalt following its oxidation. The process allows the production of a cobalt rich hydroxide precipitate assaying $45 \pm 4 \% \mathrm{Co}, 0.8 \pm 0.2 \% \mathrm{Zn}, 4.4 \pm 0.7 \% \mathrm{Cu}$, and $0.120 \pm 0.004 \% \mathrm{Cd}$ at a $61 \pm 14 \%$ Co recovery. Replicating the whole process with different feed samples allowed the identification of the critical steps in the production of the cobalt product; one of these critical steps being the control of the oxidation conditions for the selective precipitation step.
\end{abstract}

Keywords: zinc residue; cobalt hydroxide; cementation; leaching; oxidative precipitation

\section{Introduction}

The conventional roast-leach zinc extraction process yields a solid residue consisting of a mixture of zinc, copper, cadmium, and cobalt. Some zinc smelting plants process that residue [1-3] to recover the contained valuable metals. The high value of cobalt makes it an excellent candidate for a first step in the development of a process to recover the metals contained in that residue [1]. Indeed, cobalt is currently considered as a critical material [4] as it is used in the making of Li-ion batteries [1,5], increasingly strategic for the shift toward green energy or more precisely toward a 100\% electric vehicle market [4]. The «critical» status of cobalt is related to uncertainties about the supply of the metal. In fact, $60 \%$ of the world's cobalt is mined in the Congo and $80 \%$ of its production is processed in China [4]. In the case of a cobalt supply disruption due to a natural disaster, a change of government or a boycott [6], a zinc residue that contains more than $2 \%$ Co [1] becomes an interesting alternative to primary cobalt.

The extraction of cobalt from zinc plant residues is not discussed in many papers except in a recent review [1]. Few papers $[2,3,7,8]$ were found to describe processes to recover cobalt from zinc residues. Wang and Zhou described a process [2] to treat a zinc residue containing active carbon and organic compounds used to capture the cobalt and the manganese from the zinc solution prior to the $\mathrm{Zn}$ electro-winning step. The process developed for that residue consists of a washing stage followed by 
two roasting steps at different temperatures, leaching, and precipitation of iron and manganese followed by anion exchange and solvent extraction of cobalt using extractant P507. Fattahi et al. described a process [3] to extract cobalt from the zinc residues of Iranian Zn smelters that add permanganate to the zinc solution in order to oxidize $\mathrm{Co}$ (II) to $\mathrm{Co}(\mathrm{III})$ which is precipitated by increasing the $\mathrm{pH}$. The precipitated zinc residue contains about $2 \%$ Co and more than 10\% Mn. The authors [3] propose a reductive leaching followed by a precipitation of cobalt sulfide $(\mathrm{CoS})$ using $\mathrm{Na}_{2} \mathrm{~S}$ to selectively recover the cobalt from the manganese. Although the conventional approach for the purification of zinc solution is the cementation of $\mathrm{Cu}, \mathrm{Cd}$, and Co onto zinc dust [1,9], it was not possible to find in the Western literature a process dedicated to the treatment of this type of residue, although a qualitative description of a possible process can be found in [1]. Li et al. [10] studied the rate of leaching of a zinc residue but did not indicate if the residue is obtained by cementation on zinc dust and the authors did not attempt to process the leach solution to obtain a salable cobalt product.

This paper describes a processing scheme to produce a cobalt rich compound from a zinc plant residue produced by the cementation process. The objective of the test work presented in this paper is not to optimize an existing flowsheet but to propose a process to obtain a salable cobalt compound from a zinc residue produced by cementation on zinc dust. As requested by the industrial partner, the proposed process should use only open tank reactors for leaching and precipitation without resorting to solvent extraction nor ion exchange to obtain the cobalt product. This last constraint complicates the process to be developed as selective extractants are available for cobalt [1,7]. However, if the economics of the process are not favorable, the use of SX will be investigated but it is unlikely that the addition of a SX plant could move the process economics toward more profitable conditions.

\section{Materials and Methods}

\subsection{Instrumentation and Reagents}

The solid and liquid samples are assayed using a MP-AES 4200 (microwave-plasma atomic emission spectrometer) from Agilent Technology (Santa Clara, CA, USA). For solid samples, $0.5 \mathrm{~g}$ sub samples are taken and digested in aqua regia for analysis using the MP-AES. The $\mathrm{pH}$ and Eh of the solution are, respectively, measured using a Fisher Scientific accumet XL600 pH-meter (Waltham, MA, USA), an Orion $\mathrm{pH}$ probe, and an Orion Oxidation Reduction Potential (ORP) probe from Thermo scientific (Waltham, MA, USA). Table 1 presents the reagents used for the experimentation.

Table 1. Reagents used for the experimentation.

\begin{tabular}{ccc}
\hline Reagent & Composition & Brand and Purity \\
\hline Sulfuric acid & $\mathrm{H}_{2} \mathrm{SO}_{4}$ & Fisher, $98 \%$ purity \\
Sodium hydroxide & $\mathrm{NaOH}$ & Fisher, $98.8 \%$ purity \\
Ammonium persulfate & $\left(\mathrm{NH}_{4}\right)_{2} \mathrm{~S}_{2} \mathrm{O}_{8}$ & Alfa Aesar, $98 \%$ purity \\
\hline
\end{tabular}

\subsection{Provenance of the Zinc Residue}

The zinc residue used for the test work is provided by the CEZinc refinery [11] in Valleyfield, QC, Canada. Figure 1 shows the zinc extraction process and identifies the origin of the Co-bearing zinc residue. The plant processes zinc sulfide concentrates assaying more than $50 \% \mathrm{Zn}, 0-5 \% \mathrm{~Pb}$, less than $2 \% \mathrm{Cu}, 0.5 \% \mathrm{Cd}$ and from $50-200 \mathrm{~g} / \mathrm{t}$ Co. The main impurities are iron (>8\%) and sulfur $(>30 \%)$. The extraction process of zinc begins by a roasting of the zinc sulfide concentrate to oxidize sulfur into $\mathrm{SO}_{2}$ that is subsequently converted into sulfuric acid $\left(\mathrm{H}_{2} \mathrm{SO}_{4}\right)$. The roasting also transforms the zinc sulfide into zinc oxide which is soluble in weakly acidic solutions. The roasted product is leached in sequence with weak and strong sulfuric acid to solubilize the zinc oxide. The metallic impurities (Fe, $\mathrm{Cu}, \mathrm{Cd}, \mathrm{Co}$ ) follow the zinc into the solution. The solution then undergoes a neutralization, during which the solubilized iron is precipitated as jarosite [8]. The purification of the iron-free solution from 
the remaining metallic impurities is done using cementation on zinc dust [9] where copper, cadmium, and cobalt displace the zinc of the zinc powder through the reaction:

$$
M_{a q}^{2+}+\mathrm{Zn}_{s} \rightarrow \mathrm{Zn}_{a q}^{2+}+M_{s}
$$

where $M$ stands for copper, cadmium, or cobalt. The reduced copper, cadmium, and cobalt are plated onto the surface of the zinc powder. The cemented powder is separated from the solution by a leaf press filter. The recovered solid is the «Zinc Plant Residue» (ZPR) considered in the following study. This residue is currently transferred to another plant for further processing. Zinc is finally electro-won from the purified solution (See Figure 1). The spent electrolyte is recycled back to the leaching step.

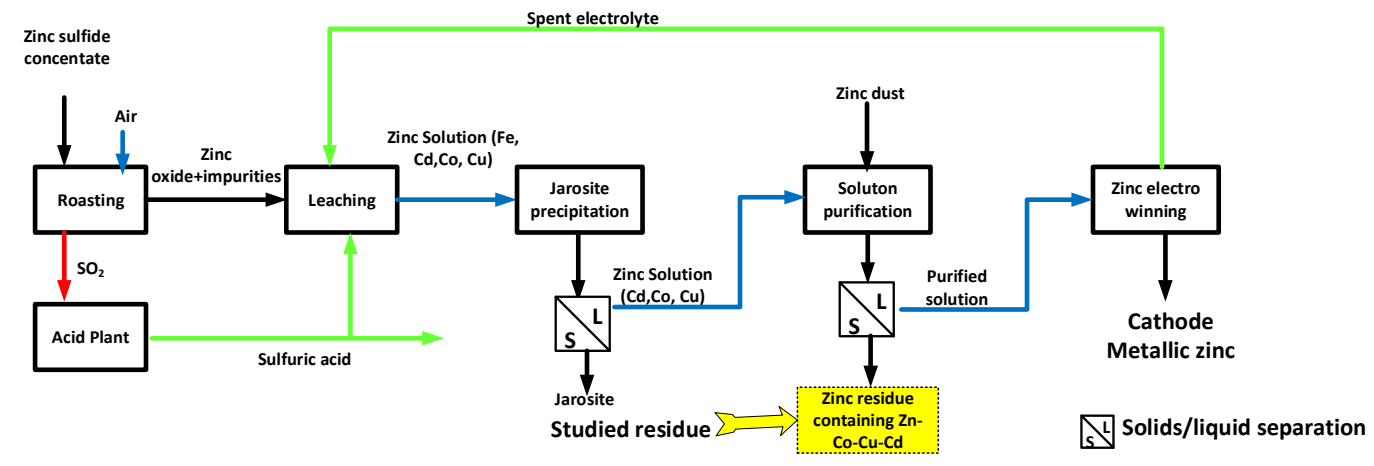

Figure 1. Simplified flowsheet of the zinc extraction process.

\subsection{Characterization of the Zinc Plant Residue (ZPR)}

A $20 \mathrm{~kg}$ sample of ZPR was collected by the CEZinc personnel at the discharge of the press filter. The sample was shipped wet to the laboratory for the test work. The received sample was split wet into ten parts after spreading the material onto a plastic sheet. One $2 \mathrm{~kg}$ sample was put in an oven for drying overnight and the remaining material was kept wet for the subsequent test work. A portion of the dried sample is shown in Figure 2a. The material is strongly agglomerated with practically unbreakable lumps. Sulfuric acid and sulfates are likely responsible for the observed particles binding. It rapidly appeared that this material could not be characterized (chemical composition, size distribution, etc.) as is and it was decided to wash the residue in water to remove any excess of sulfuric acid before drying. Washing was carried out by mixing $500 \mathrm{~g}$ of wet residue in $2700 \mathrm{~mL}$ of water (15\% solids in mass) in a beaker for $90 \mathrm{~min}$ at room temperature $\left(25^{\circ} \mathrm{C}\right)$. The washed residue was separated from the solution by vacuum filtration and dried overnight in an oven. The dried washed residue is shown in Figure $2 \mathrm{~b}$ and is found to be more amenable to characterization than the raw residue.

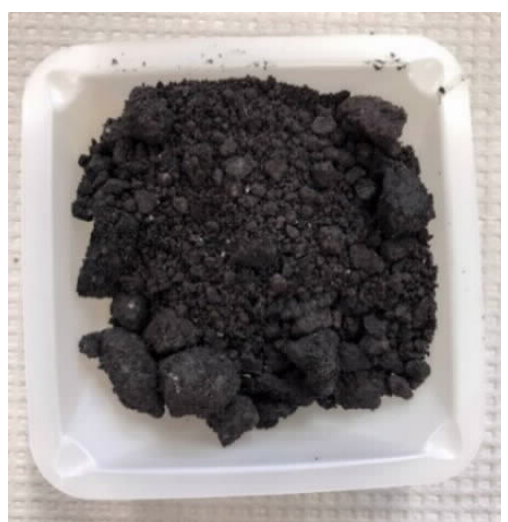

(a)

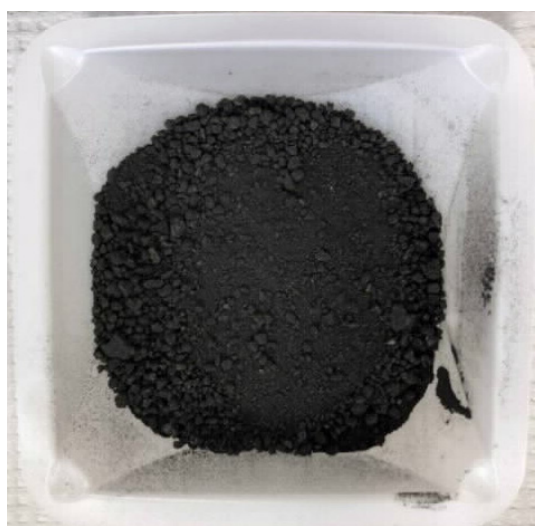

(b)

Figure 2. ZPR as is and after washing with water. (a) Raw residue after drying; (b) Residue after washing and drying. 


\subsubsection{Specific Gravity}

The measured specific gravity (Gas pycnometer, HumiPyc model 2 from Instruquest, Coconut Creek, FL, USA) of the washed ZPR is $3.95 \mathrm{~g} / \mathrm{cm}^{3}$. Since the densities of zinc and of the cemented metals are all above $5 \mathrm{~g} / \mathrm{cm}^{3}$ this result indicates that the residue is not made exclusively of pure metals.

\subsubsection{Size Distribution}

Figure 3 shows the particle size distribution obtained by sieving the washed ZPR on a Tyler screen series from $1.2 \mathrm{~mm}$ down to $0.038 \mathrm{~mm}$. The ZPR is coarse with a $\mathrm{D}_{80}$ of about $900 \mu \mathrm{m}$. The material coarseness will pose a problem for the sampling for assaying of the residue. Indeed, since assaying of the sample implies collecting a $0.5-1.0 \mathrm{~g}$ sample for the digestion prior to analysis using the emission spectrometer (Section 2.1), one can expect a significant variability in the assays of the residue due to the fundamental error of sampling [12]. For ore type material, this error is reduced by pulverizing the sample prior to sampling. However, the metallic and ductile nature of the ZPR makes impossible the pulverization of the sample, and thus one should expect a variability in the assays that data reconciliation [13-16] as applied here should be able to attenuate.

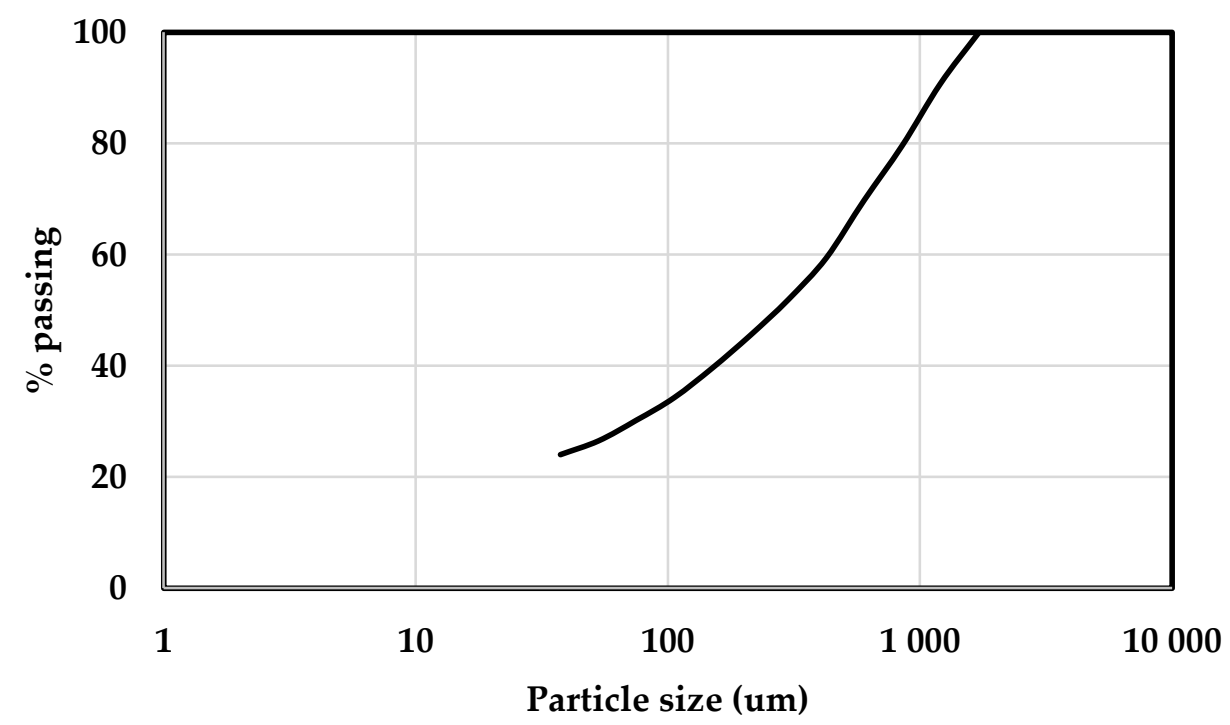

Figure 3. Size distribution of the residue.

\subsubsection{Chemical Composition}

Table 2 gives the chemical composition of the ZPR sample. The measured assays of the sample are compared (see Table 2) to the typical composition of the ZPR provided by the CEZinc plant. The general proximity of the sample composition with the typical composition of the residue provided by CEZinc confirms that the received sample is representative of the residue usually released by the plant. The difference in the composition is attributed to the washing as discussed later. The Co content is consistent with typical ZPR from other zinc smelters [1-3]. 
Table 2. Composition of the ZPR.

\begin{tabular}{ccccc}
\hline Elements & $\begin{array}{c}\text { CEZ Typical Composition } \\
\text { \% }\end{array}$ & \multicolumn{3}{c}{ Sample Composition * } \\
\% \\
\hline $\mathrm{Zn}$ & $20-25$ & 16.0 & \pm & 0.5 \\
$\mathrm{Cd}$ & $2-6$ & 3.5 & \pm & 0.2 \\
$\mathrm{~S}$ & - & 5.7 & \pm & 0.8 \\
$\mathrm{Cu}$ & $15-25$ & 11.9 & \pm & 0.4 \\
$\mathrm{Ca}$ & - & 0.76 & \pm & 0.04 \\
$\mathrm{Co}$ & $2-4$ & 1.7 & \pm & 0.1 \\
$\mathrm{Ni}$ & $0-2$ & 0.44 & \pm & 0.04 \\
$\mathrm{Fe}$ & $0-1$ & 0.34 & \pm & 0.02 \\
$\mathrm{Mn}$ & - & 0.22 & \pm & 0.01 \\
$\mathrm{~Pb}$ & $9-12$ & 4.0 & \pm & 0.1 \\
\hline
\end{tabular}

*: Average \pm standard deviation of three samples.

\subsubsection{X-ray Diffraction (XRD)}

Figure 4 shows the XRD pattern (Instrument: Aeris, Malvern Panalytical (Malvern, UK) obtained for the residue. The XRD shows the presence of metallic zinc, copper, and possibly metallic lead. The peaks for $\mathrm{Cd}$ and $\mathrm{Co}$ are not visible due to the low contents of these elements. The presence of $\mathrm{Pb}$ is confirmed by the assays (see Table 2) and is reported under the form of $\mathrm{PbO}_{2}$ for the residue of an Iranian zinc smelter [3] and under the form of $\mathrm{PbSO}_{4}$ [10] for a Chinese zinc residue. The XRD results of Figure 4 also show the presence of copper, zinc, and calcium sulfates likely responsible for the observed low specific gravity of the residue (Section 2.3.1). These sulfates, except gypsum, could be completely removed by a longer or slightly acidic or hot water wash of the residue as reported in [2].

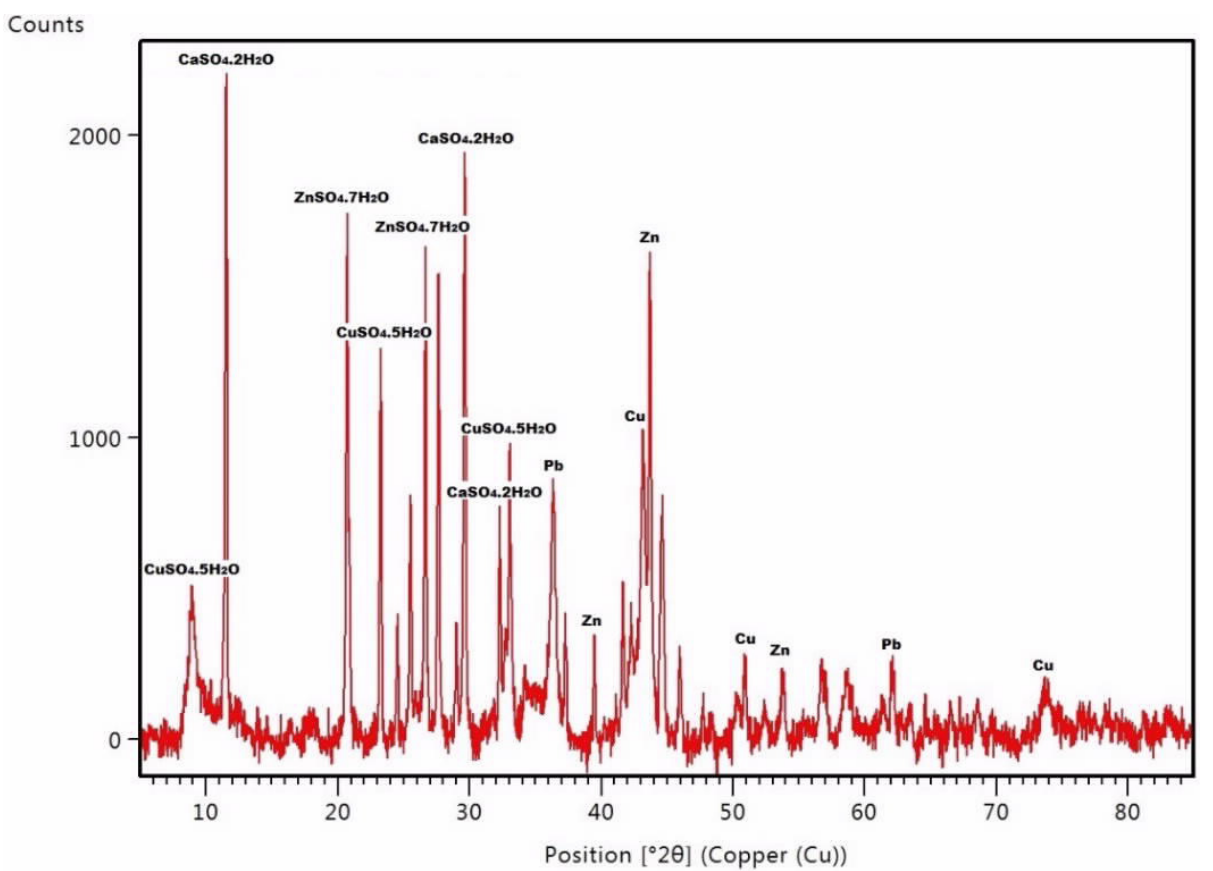

Figure 4. XRD powder pattern of the CEZinc ZPR.

\section{Results}

\subsection{Washing of the ZPR}

The first step of the proposed process is the washing of the ZPR. Initially done to eliminate the sulfuric acid from the ZPR, the washing step provides an economic way to pre-concentrate the 
cobalt by allowing a partial elimination of the soluble zinc and cadmium sulfates contained in the ZPR. The results of a washing test are shown in Figure 5 and Table 3. Washing is carried out at room temperature using water at $15 \%$ solids in mass. Figure 5 shows the measured concentrations of $\mathrm{Zn}, \mathrm{Cd}$, $\mathrm{Ca}, \mathrm{Co}$, and $\mathrm{Cu}$ during washing. The solution $\mathrm{pH}$ falls from 7.2 to 6.3 during the washing step due to the release of the residual sulfuric acid. Table 3 gives the proportions of metals removed from the ZPR calculated using:

$$
D_{m}=100 \frac{V x_{m}}{V x_{m}+W_{\mathrm{ZPR}} y_{\mathrm{ZPR}}}
$$

where $D_{m}$ is the dissolved proportion of metal $m, V$ is the volume (L) of the wash solution, $x_{m}$ the metal content $(\mathrm{g} / \mathrm{L})$ in the solution. $W_{Z P R}$ and $y_{Z P R}$ are, respectively, the weight $(\mathrm{g})$ and the fraction of metal $m$ in the dried washed ZPR. Results presented in Table 3 show that, respectively, 20\% and 43\% of the zinc and cadmium contained in the raw ZPR are removed by a 30 min wash. About $4 \%$ of the cobalt contained in the ZPR is lost during the operation. Higher impurity removal can be achieved by washing the ZPR for 90 min but at increased cobalt losses as shown in Figure 5. The zinc is likely under an insoluble metallic form as metallic zinc dust is used for the cementation, while cadmium is likely present as a sulfate. The $4 \%$ Co dissolution is an indication that some cobalt is under the form of sulfate, with the remaining being metallic. The washing step can be viewed as a selective leaching operation for which the leaching conditions are adjusted to target specific metals [1,2]. The use of diluted acid in replacement of water could yield a better elimination of zinc and cadmium at the expenses of more important cobalt losses into the wash solution [10].

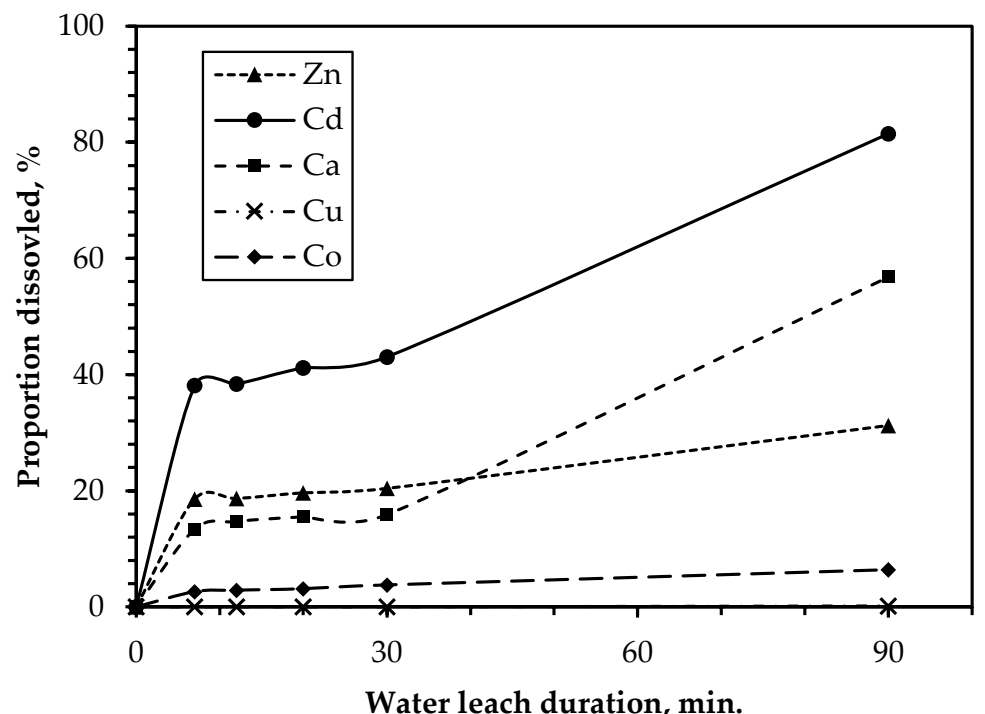

Figure 5. Dissolved proportion of metals in time $\left(25^{\circ} \mathrm{C}, 15 \%\right.$ solids in mass).

Table 3. Dissolved metals after $30 \mathrm{~min}$ of washing with water $\left(25^{\circ} \mathrm{C}, 15 \%\right.$ solids in mass).

\begin{tabular}{cccc}
\hline Metal & \multicolumn{3}{c}{ \% Dissolved * } \\
\hline $\mathrm{Zn}$ & 20 & \pm & 3 \\
$\mathrm{Cd}$ & 43 & \pm & 2 \\
$\mathrm{Cu}$ & 0.03 & \pm & 0.02 \\
$\mathrm{Ca}$ & 16 & \pm & 1 \\
$\mathrm{Co}$ & 4 & \pm & 1 \\
$\mathrm{Ni}$ & 2 & \pm & 1 \\
$\mathrm{Fe}$ & 0.4 & \pm & 0.2 \\
$\mathrm{Mn}$ & 84 & \pm & 3 \\
$\mathrm{~Pb}$ & 0.1 & \pm & 0.2 \\
\hline
\end{tabular}

*: average \pm standard deviation of three tests. 


\subsection{Preparation of ZPR Samples for the Co Extraction Tests}

The leaching tests are carried out using samples prepared by washing $75 \mathrm{~g}$ of raw ZPR for $30 \mathrm{~min}$ using the above described approach. The washed material is dried at low temperature in an oven. The use of $75 \mathrm{~g}$ batches was found to be a good compromise between the variability of the $75 \mathrm{~g}$ batch composition [17] and the mass of material to be manipulated during the experimentation. Table 4 gives the assays obtained by assaying three (3) randomly selected $75 \mathrm{~g}$ batches.

Table 4. Chemical assays (\%) of three randomly selected feed samples (Smp = Sample; Avg = Average; Std-dev $=$ Standard deviation RSD: = Std-Dev/Avg).

\begin{tabular}{ccccccc}
\hline Elements & Smp \#1 & Smp \#2 & Smp \#3 & Avg & Std-Dev & RSD (\%) \\
\hline $\mathrm{Zn}$ & 16.4 & 16.2 & 15.5 & 16.0 & 0.5 & 3 \\
$\mathrm{Cd}$ & 3.7 & 3.5 & 3.3 & 3.5 & 0.2 & 6 \\
$\mathrm{Cu}$ & 11.5 & 12.1 & 12.2 & 11.9 & 0.4 & 3 \\
$\mathrm{Ca}$ & 0.80 & 0.77 & 0.72 & 0.76 & 0.04 & 5 \\
$\mathrm{Co}$ & 1.68 & 1.80 & 1.63 & 1.71 & 0.09 & 5 \\
$\mathrm{Ni}$ & 0.47 & 0.47 & 0.40 & 0.44 & 0.04 & 9 \\
$\mathrm{Fe}$ & 0.36 & 0.34 & 0.31 & 0.34 & 0.02 & 6 \\
$\mathrm{Mn}$ & 0.23 & 0.21 & 0.23 & 0.22 & 0.01 & 5 \\
$\mathrm{~Pb}$ & 3.8 & 4.1 & 4.0 & 4.0 & 0.1 & 3 \\
\hline
\end{tabular}

\subsection{Leaching of the Washed ZPR}

The next step of the process is to leach the metals out of the ZPR into an aqueous solution from whichi it will be possible to separate the cobalt from the other metals. The leaching tests are conducted in a mechanically agitated beaker for $30 \mathrm{~min}$ using a weight $\mathrm{L} / \mathrm{S}$ ratio of $15 / 1$ at $80^{\circ} \mathrm{C}$. Leaching tests are carried out with sulfuric acid as it is the acid used in the zinc plant that provided the ZPR. Table 5 gives the average proportion of metals dissolved ( \pm standard deviation) of three (3) leaching tests and the average metal contents in the liquor. About $65 \%$ of the solids in the ZPR are dissolved during the leaching process with $98 \%$ of the cobalt effectively leached off the ZPR, a performance similar to that reported in [10].

Table 5. Proportion of the metals dissolved during the leaching of the ZPR (Average ( \pm standard deviation) of the results of three (3) leaching tests and the average composition of the liquor (Ratio L/S: $\left.15 / 1 ; 100 \mathrm{~g} / \mathrm{L} \mathrm{H}_{2} \mathrm{SO}_{4}, \mathrm{Eh}=90 \mathrm{mV}, \mathrm{pH}=0.2,30 \mathrm{~min}, 80^{\circ} \mathrm{C}\right)$.

\begin{tabular}{cllcc}
\hline Species & \multicolumn{3}{c}{$\%$ Dissolved } & Liquor Concentration $(\mathbf{m g} / \mathbf{L})$ \\
\hline Solids & 65 & \pm & 1 & \\
$\mathrm{Zn}$ & 97.1 & \pm & 0.4 & 11,800 \\
$\mathrm{Cd}$ & 91 & \pm & 2 & 370 \\
$\mathrm{Cu}$ & 37 & \pm & 3 & 3600 \\
$\mathrm{Ca}$ & 88 & \pm & 3 & 252 \\
$\mathrm{Co}$ & 97 & \pm & 1 & 1170 \\
$\mathrm{Ni}$ & 97 & \pm & 1 & 345 \\
$\mathrm{Fe}$ & 98 & \pm & 2 & 270 \\
$\mathrm{Mn}$ & 91 & \pm & 16 & 26 \\
$\mathrm{~Pb}$ & 0.2 & \pm & 0.3 & 6 \\
\hline
\end{tabular}

\subsection{Selective Precipitation of the Cobalt from the Pregnant Liquor Solution}

The main impurities in the pregnant liquor solution are $\mathrm{Zn}, \mathrm{Cd}, \mathrm{Ni}, \mathrm{Fe}$, and $\mathrm{Cu}$ (Table 5). The approach used to selectively separate cobalt from these elements begins with an oxidation of iron and manganese to precipitate of these oxidized elements by increasing the $\mathrm{pH}$ near 3.0 while $\mathrm{Cu}, \mathrm{Zn}$, $\mathrm{Cd}$, and $\mathrm{Co}$ (II) remain in the solution. The next step is to oxidize $\mathrm{Co}(\mathrm{II})$ to $\mathrm{Co}$ (III) and to precipitate $\mathrm{Co}(\mathrm{III})$ by increasing the $\mathrm{pH}$ above 3.0 leaving $\mathrm{Zn}, \mathrm{Cd}$, $\mathrm{Ni}$ and $\mathrm{Cu}$ in the solution. 
Ammonium PerSulfate or APS $\left(\left(\mathrm{NH}_{4}\right)_{2} \mathrm{~S}_{2} \mathrm{O}_{8}\right)$, as discussed in $[1,8]$, provides the required oxidation potential for iron, manganese and subsequently cobalt. The sequence of the steps followed to precipitate the cobalt is shown in Figure 6.

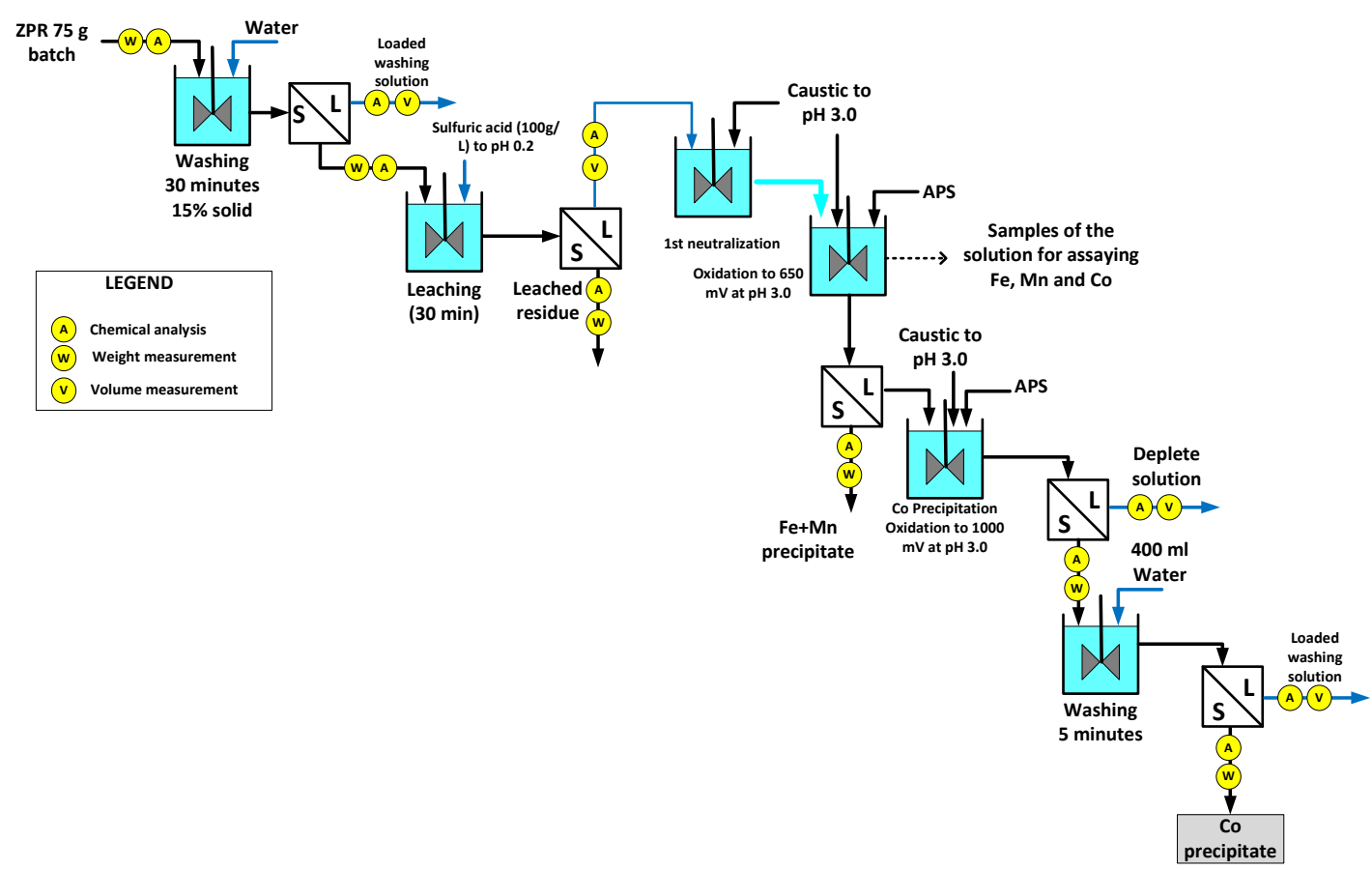

Figure 6. Process for the extraction of cobalt from the ZPR.

\subsubsection{Precipitation of Fe-Mn}

Sodium hydroxide is firstly added to the pregnant liquor solution to bring the $\mathrm{pH}$ to 3.0. APS is then added to the solution to increase the Redox potential from 90 to $650 \mathrm{mV}$. During the oxidation process, the $\mathrm{pH}$ of the solution is maintained at 3.0 by a regular addition of $\mathrm{NaOH}$. Samples of the solution were collected at different Eh values and analyzed for Fe, Mn, and Co. As anticipated [1] Fe and Mn precipitate prior to Co a behavior confirmed by the variations of the metal contents in the solution as shown in Figure 7. According to Figure 7, the optimal Eh for the precipitation of Fe and $\mathrm{Mn}$ without precipitation of Co is $650 \mathrm{mV}$ and the minimum Eh for the precipitation of Co is $1000 \mathrm{mV}$. These Eh values are coherent with those reported in [1]. Table 6 gives the proportions of the metals in the leached solution that are removed by the oxidation to $650 \mathrm{mV}$. Iron and manganese are almost completely removed from the solution. Ideally, cobalt should not be precipitated at this stage; however, it was observed that a close control of the Eh was not always possible as the Redox probe shows a significant measurement variability causing cobalt losses ( 17\%) in the Fe-Mn precipitate. The difficulty in the control of the Eh is attributed to the probe and to its sensitivity to the APS addition. Indeed, a small addition of APS can make a large local step in the Redox potential of the solution. It is likely that a process solely based on the use of an APS dosage [1,8] is not recommended to achieve a selective separation. Cleary the oxidant addition should be based on a reliable measurement of the ReDox potential of the solution and not on the dosage of the oxidant.

Once the Redox potential reaches $650 \mathrm{mV}$, the addition of APS is stopped and the iron and manganese precipitate are removed by filtration (see Figure 6). The filtration of the sludgy Fe-Mn precipitate is difficult and is believed to be one of the reasons for the loss of cobalt at this stage. Ensuring a rapid and adequate filtration of the solution after the end of the reaction seems critical to limit cobalt losses. The solution from that solid/liquid separation advances to the cobalt precipitation step (Figure 6). Results of Table 6 show that Mn and Fe are effectively removed from the solution at the expenses of some cobalt losses. The large standard deviation observed for the fraction of 
cobalt precipitated is attributed to Eh measurement problems as discussed above and difficulties in the filtration of the precipitate from one test to another one. Improving on the accuracy of the Eh measurement method and of the solids/liquid separation of the Fe-Mn precipitate could significantly improve the global recovery of cobalt.

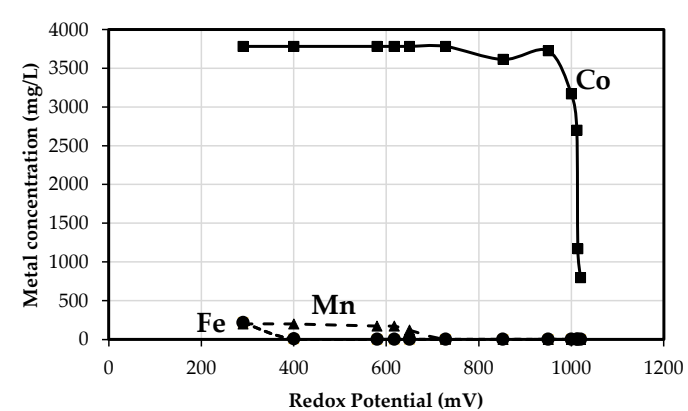

(a)

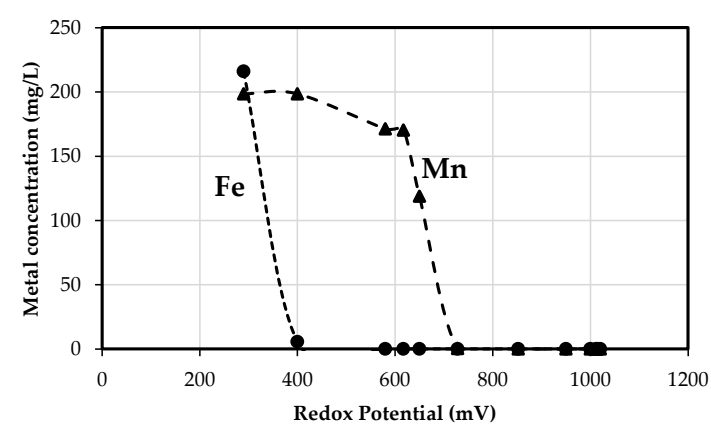

(b)

Figure 7. Precipitation of Fe and Mn with increasing the Eh while maintaining a pH of 3.0 (a) Fe, Mn, and Co contents in the solution during the oxidation to $1000 \mathrm{mV}$. (b) Fe and Mn contents in the solution during the oxidation below $1000 \mathrm{mV}$.

Table 6. Metal precipitation during the oxidation for Fe-Mn removal of the leach solution (Average ( \pm standard deviation) results of three (3) tests ( $\mathrm{Eh}=90$ to $650 \mathrm{mV}, \mathrm{pH}=3.0,80^{\circ} \mathrm{C}, 15 \mathrm{~min}$ ).

\begin{tabular}{|c|c|c|c|}
\hline \multirow{2}{*}{$\frac{\text { Species }}{\mathrm{Zn}}$} & \multicolumn{3}{|c|}{$\%$ Precipitated } \\
\hline & 0.3 & \pm & 0.2 \\
\hline $\mathrm{Cd}$ & 0.6 & \pm & 0.2 \\
\hline $\mathrm{Cu}$ & 1.1 & \pm & 0.4 \\
\hline $\mathrm{Ca}$ & 1.1 & \pm & 0.6 \\
\hline $\mathrm{Co}$ & 17 & \pm & 8 \\
\hline $\mathrm{Ni}$ & 0.6 & \pm & 0.3 \\
\hline $\mathrm{Fe}$ & 80 & \pm & 20 \\
\hline $\mathrm{Mn}$ & 90 & \pm & 10 \\
\hline
\end{tabular}

\subsubsection{Precipitation of Co}

The cobalt precipitation is carried out by adding APS to bring the Redox to $1000 \mathrm{mV}$ and keeping the solution at $80^{\circ} \mathrm{C}$ to accelerate the precipitation [1]. The precipitation of cobalt under the form of $\mathrm{CoOOH}$ is slow as shown in Figure 8a. This observed behavior is consistent with previously reported results [1] reproduced in Figure $8 \mathrm{~b}$. Table 7 gives the variation of the solution composition from the leach step to the $\mathrm{Co}$ precipitation one. $\mathrm{Zn}, \mathrm{Cd}$, and $\mathrm{Cu}$ remain in the solution while cobalt precipitates with some of the iron and manganese remaining in the solution after the first oxidation step. Table 8 gives the proportions of the different metals precipitated during the cobalt precipitation step. About $2 \%$ of the copper precipitates with the cobalt and represents a critical impurity as discussed later. The fact that the observed Co precipitation rate in Figure 8 is significantly less than that reported in [1] is an indication that there is room to improve the proposed processing scheme in order to reduce the precipitation time and subsequently the volume of the precipitation vessels for a continuous process. 


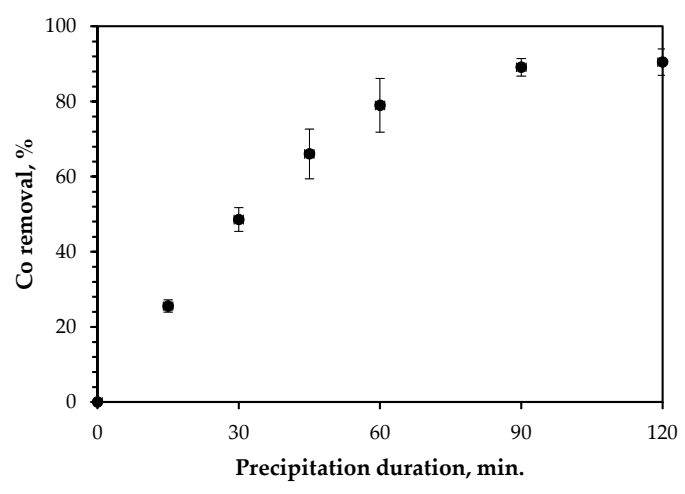

(a)

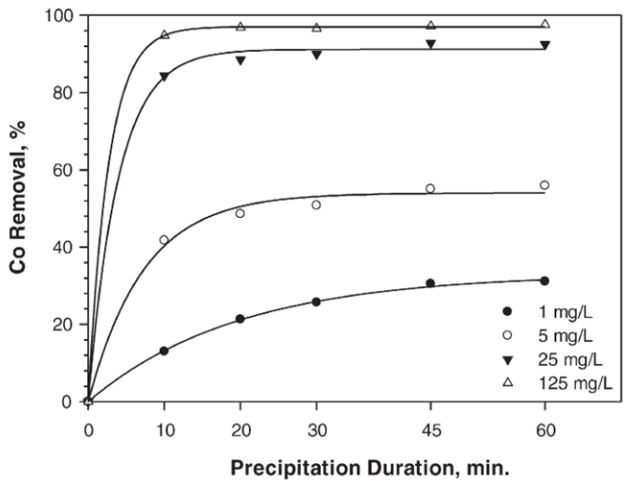

(b)

Figure 8. Cobalt precipitation rates. (a) Observed rate of Co precipitation $(\mathrm{pH}=3.0, \mathrm{Eh}=1000 \mathrm{mV}$, $80^{\circ} \mathrm{C}, 1 \mathrm{~g} / \mathrm{L} \mathrm{Co}$ ). (b) Rates of Co precipitation reported in [1] B-0.

Table 7. Composition of the solutions from the ZPR leach, Fe-Mn and Co precipitation steps.

\begin{tabular}{cccccccc}
\hline & \multicolumn{7}{c}{ All Concentrations in mg/L } \\
\hline Solution & Volume $(\mathbf{m L})$ & Zn & Cd & Cu & Co & Fe & Mn \\
\hline Leach solution & 841 & 11,800 & 370 & 3600 & 1170 & 270 & 26 \\
After Fe-Mn ppt & 944 & 10,511 & 327 & 3200 & 860 & 46 & 1.3 \\
After Co ppt & 975 & 10,111 & 318 & 3000 & 84 & 16 & 0.4 \\
\hline
\end{tabular}

Table 8. Metal precipitation during the cobalt precipitation stage (Average \pm standard deviation) for three (3) tests $\left(\mathrm{Eh}=1000 \mathrm{mV}, \mathrm{pH}=3.0,80^{\circ} \mathrm{C}, 120 \mathrm{~min}\right)$.

\begin{tabular}{cccc}
\hline Species & \multicolumn{3}{c}{$\%$ Precipitated } \\
\hline $\mathrm{Zn}$ & 0.4 & \pm & 0.1 \\
$\mathrm{Cd}$ & 1 & \pm & 0.3 \\
$\mathrm{Cu}$ & 2 & \pm & 1 \\
$\mathrm{Ca}$ & 1 & \pm & 0.4 \\
$\mathrm{Co}$ & 89 & \pm & 3 \\
\hline
\end{tabular}

\subsubsection{Washing and Composition of the Cobalt Precipitate}

The cobalt precipitate is washed with water at $80^{\circ} \mathrm{C}$ at $1 \%$ solids for $5 \mathrm{~min}$, filtered, dried overnight, weighed, and assayed. Table 9 gives the composition of the cobalt product obtained from 3 independent tests. Table 9 compares the average composition of the cobalt product to a target cobalt hydroxide feed for a cobalt refinery [18]. Results show that some tunings (likely at the cobalt precipitation stage) of the process are still required to lower the zinc and copper contents to meet the composition of the feed material for the Co-refinery.

Table 9. Composition (\%) of the produced cobalt hydroxide and specifications for the feed of a custom cobalt refinery.

\begin{tabular}{ccccccccc}
\hline Material & Co & Cd & $\mathbf{C u}$ & $\mathbf{Z n}$ & $\mathbf{F e}$ & $\mathbf{M n}$ & $\mathbf{N i}$ & $\mathbf{P b}$ \\
\hline $\begin{array}{c}\text { Produced Co } \\
\text { hydroxide }\end{array}$ & $45 \pm 4$ & $0.120 \pm 0.004$ & $4.4 \pm 0.7$ & $0.8 \pm 0.2$ & $2 \pm 1$ & $<0.1$ & $<0.1$ & $0.3 \pm 0.1$ \\
$\begin{array}{c}\text { Custom refinery Co } \\
\text { hydroxide feed [19] }\end{array}$ & 23.2 & n.a. & 1.61 & 0.19 & 2.39 & 3.27 & 0.39 & n.a. \\
\hline
\end{tabular}

*: Average \pm standard deviation of three (3) replicated tests. 
The XRD powder pattern of the cobalt product is shown in Figure 9. Results confirm that the produced material is under the form of $\mathrm{CoO}(\mathrm{OH})$ and $\mathrm{Co}(\mathrm{OH})_{2}$. The presence of these compounds was expected based on observations from other researchers [1].

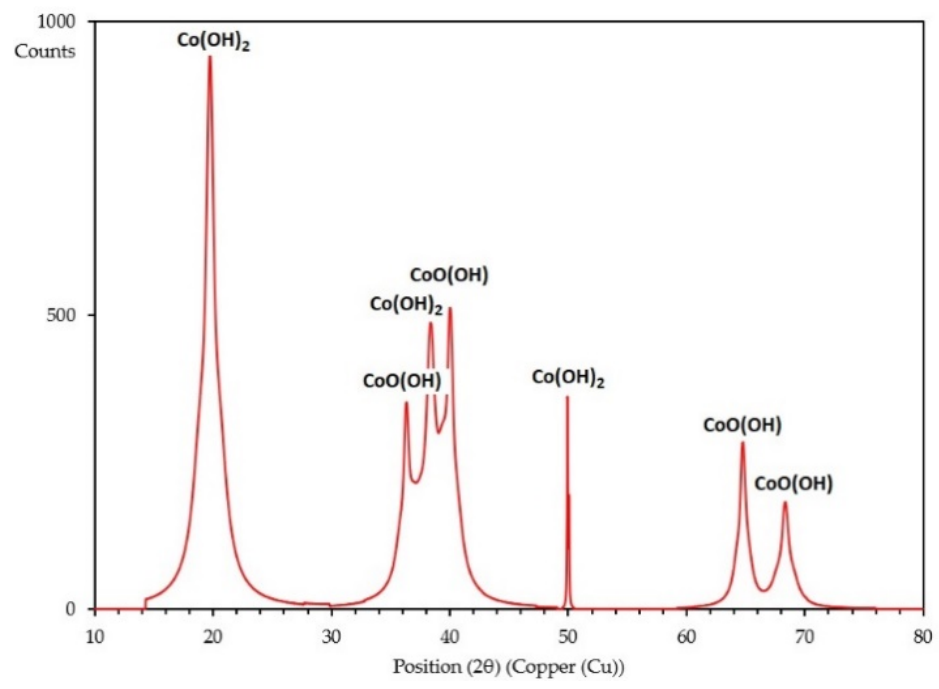

Figure 9. XRD powder pattern of the cobalt product.

\subsection{Overall Process Performance and Quality of the Product}

The process flow sheet for the extraction of cobalt from the ZPR is shown in Figure 10. The flowsheet has similarities with the flowsheet presented in [1]. The similarity between the two flowsheets developed independently is an indication that this processing scheme is a viable route for the recovery of cobalt from a ZPR produced by cementation on zinc dust.

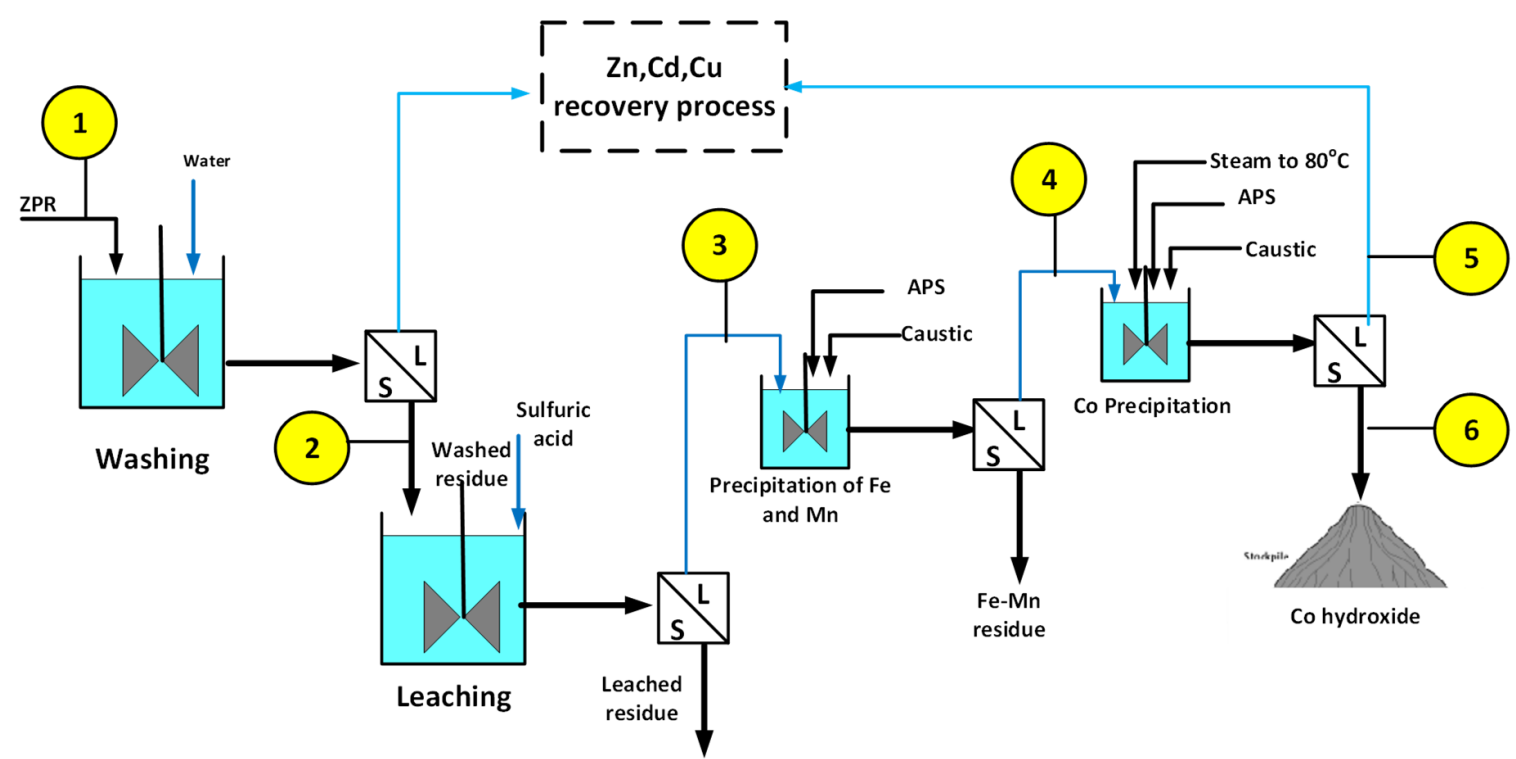

Figure 10. ZPR processing circuit to extract cobalt (See Table 10 for the composition of streams 1-6).

In order to assess the robustness of the proposed process, the whole processing sequence of Figure 10 was repeated with three ZPR feed samples. The previous sections gave the results of the repetitions obtained for the various stages of the process. Table 10 summarizes these results in terms of cobalt distribution. The repetitions show that the critical step in the proposed process is the oxidation/precipitation of the iron and manganese prior to the cobalt precipitation. The main cobalt 
losses occur at the Fe-Mn precipitation step. A problem or inaccuracy in the measurement of the Redox potential and the difficulties in the filtration of the Fe-Mn sludge cause some Co precipitation and an incomplete removal of impurities that will subsequently contaminate the cobalt product. Cobalt losses also occur at the final precipitation step, where recovery could be improved by using a $\mathrm{pH}$ above 3.0 and allowing more time for precipitation [1]. However, the use of a higher $\mathrm{pH}$ and of an increase precipitation time may cause more impurities to precipitate with the cobalt. This optimization problem of maximizing Co recovery under the constraint of an acceptable product purity can be adequately tackled down using a factorial Design Of Experiments (DOE) [19] if the process is to be continued with an optimization phase. The aspect of the process sensitivity to operating conditions, particularly the control of the Redox potential, addressed here is seldom discussed in the literature dealing with the recovery of cobalt from a ZPR, while it is as important as the process itself, especially if it is to go on to piloting.

Table 10. Distribution (\%) of the cobalt in the process streams of the circuit of Figure 9.

\begin{tabular}{cccc}
\hline Process Stream & Stream Number as in Figure 10 & Avg. & Std-Dev \\
\hline ZPR & 1 & 100 & 100 \\
Washed solids ZPR & 2 & 86 & 3 \\
Leach solution & 3 & 84 & 4 \\
Co ppt feed solution & 4 & 70 & 10 \\
Spent solution from Co ppt & 5 & 7 & 1 \\
Cobalt hydroxide & 6 & 62 & 14 \\
\hline
\end{tabular}

In summary, the proposed processing flow sheet yields a Co product assaying $45 \pm 4 \%$ Co at a recovery of $62 \%$. Improvements to the reproducibility of the method can be achieved by improving the control of the Redox potential and the solids/liquid separation of the precipitated Fe-Mn sludge. These results cannot be compared to those of other processes used for processing a ZPR produced by cementation on zinc dust, as it was not possible to find such data in the literature.

Ideally, to avoid paying refining charges from the selling of the cobalt hydroxide product to a custom Co refinery, one should aim at producing electrolysis-grade cobalt at the end of the ZPR-Co process. The concentration of cobalt in the solution released by the $\mathrm{S} / \mathrm{L}$ separation of the Fe-Mn precipitate is low at $3 \mathrm{~g} / \mathrm{L}$, and should be increased to at least $45 \mathrm{~g} / \mathrm{L} \mathrm{[20]} \mathrm{to} \mathrm{allow} \mathrm{Co} \mathrm{electro-winning.}$ Solvent Extraction (SX) is an approach to increase the solution concentration and remove some of the accompanying impurities (See Table 9). The other option is to stock pile the produced Co hydroxide and to dissolve it under reducing conditions to convert $\mathrm{Co}$ (III) into Co(II) with a controlled amount of sulfuric acid to generate the solution to feed the electrolytic cells. Figure 11 shows the two options.

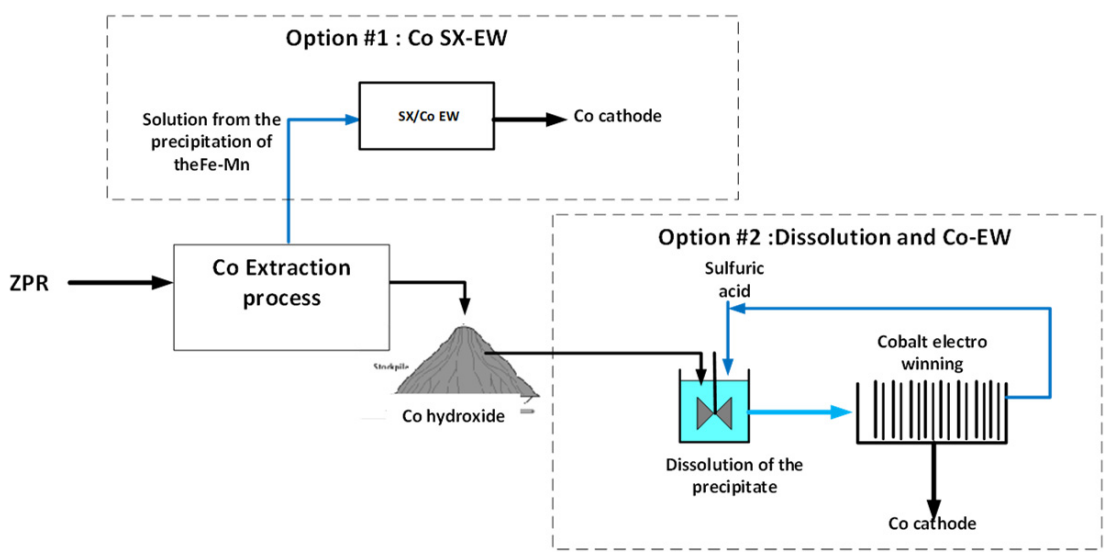

Figure 11. Processing options to produce electrolytic cobalt. 


\subsection{Economics of the Process}

The analysis presented in this section focuses only on the operating costs of the process of Figure 10. It is a preliminary analysis and the calculated costs should be considered as Class 5 estimates (AACE International). Results are used to anticipate the economic viability of the process and decide on the continuation of the laboratory test work to optimize the proposed ZPR-Co process.

A cobalt price of 30.20 USD/kg (LME Price August 2020) is used to estimate the revenues that can be generated by processing the ZPR. The Net Smelter Return, if the cobalt hydroxide is to be sold to a refinery, is estimated by assuming that $90 \%$ of the cobalt in the hydroxide is payable and that the refining charges are $3.00 \mathrm{CAD} / \mathrm{kg}$ of Cobalt hydroxide. If the cobalt content of the produced Co hydroxide is $45 \%$ (see Table 9 ) then the revenues (assuming an exchange rate of 1.25 CAD/USD) generated per $\mathrm{kg}$ of cobalt hydroxide are:

$$
N S R=0.9 \times 0.45 \times 30.2 \times 1.25-3=\frac{12.28 \text { CAD } \$}{\mathrm{~kg} \text { of Co hydroxide }},
$$

Since the test work has shown that the processing of $75 \mathrm{~g}$ of ZPR yields $1.2 \mathrm{~g}$ of Co hydroxide, the potential revenues per $\mathrm{kg}$ of $\mathrm{ZPR}$ are $0.20 \mathrm{CAD} / \mathrm{kg} \mathrm{ZPR}$.

The operating costs considered here are due to the reagents and exclude the energy costs for heating the solution at the precipitation stage. Table 11 gives the calculated operating costs per $\mathrm{kg}$ of ZPR. The reagent costs are probably over-estimated as purchasing the sulfuric acid may not be required. Indeed some spent zinc electrolyte could be used for the Co process (see Figure 1). Additionally, it is very likely that recycling some of the solution streams of the ZPR-Co process could allow a reduction in the consumption of caustic and APS. This preliminary evaluation shows that the proposed process is not viable but the process certainly deserves to be optimized to increase the overall cobalt recovery and to reduce the consumption of APS that is the main contributor to the operating costs. The option of producing metallic cobalt rather than cobalt hydroxide should also be investigated.

Table 11. Preliminary estimation of the operating costs for the ZPR-Co process of Figure 9. (The reagent prices were obtained from quotations dating of 2019 and are used here only to give an order of magnitude).

\begin{tabular}{cccc}
\hline Reagent & Consumption (kg/kg of ZPR) & Price CAD\$/kg & CAD\$/kg ZPR \\
\hline $\mathrm{H}_{2} \mathrm{SO}_{4}$ & 1.9 & 0.170 & 0.032 \\
$\mathrm{NaOH}$ & 0.07 & 0.80 & 0.056 \\
$\mathrm{APS}$ & 0.25 & 0.85 & 0.22 \\
Total costs & - & - & 0.30 \\
\hline Gross revenues & - & - & 0.20 \\
\hline Benefits (losses) & - & - & $(0.10)$ \\
\hline
\end{tabular}

\subsection{Residues of the ZPR-Co Process}

The proposed process generates two solid residues (the ZPR leached residue, the Fe-Mn precipitate) and two liquid effluents (the solutions from the ZPR washing and from the Co precipitation as indicated in Figure 12. Table 12 gives the compositions of the liquid and solid residues. The copper content of the ZPR leached solids is $36 \%$, which is above the copper content of the ZPR (see Table 2). If the metals of the reject solutions were to be precipitated under the form of hydroxides by increasing the $\mathrm{pH}$ above 9.0, the precipitate would assay $13 \% \mathrm{Cu}$, which is still in the range of the ZPR copper content. Thus, two of the residues of the ZPR-Co process could possibly be used as copper sources and possibly be sold to a $\mathrm{Cu}$ smelter. 


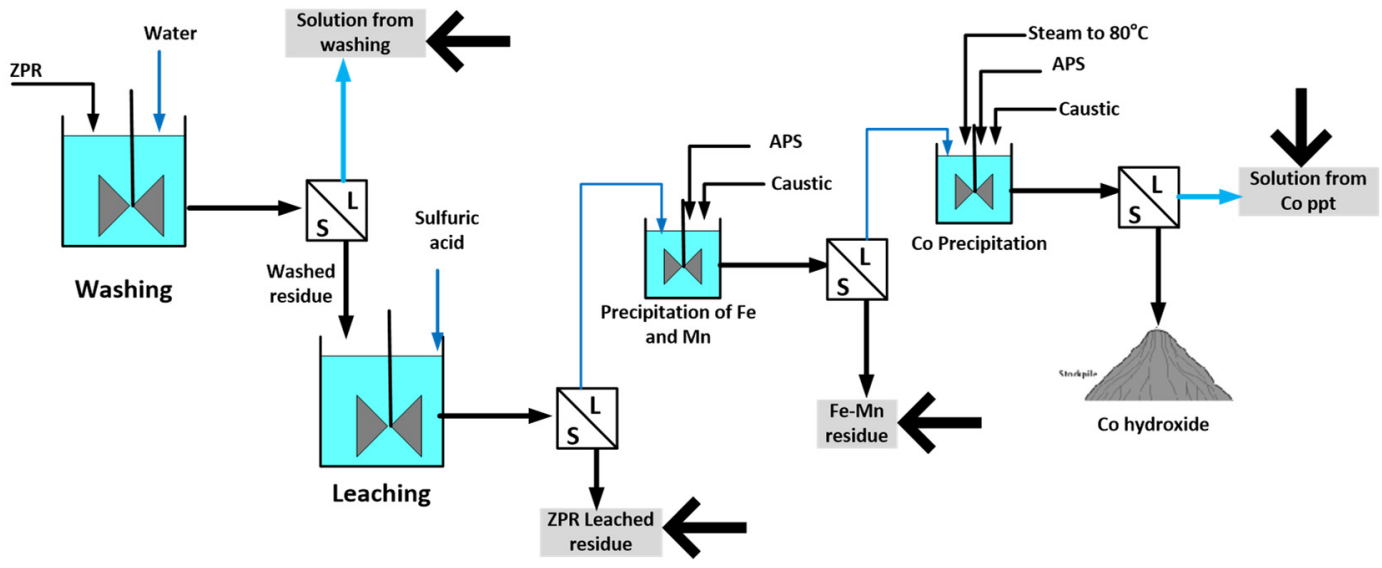

Figure 12. Liquid and solid residues generated by the ZPR-Co process.

Table 12. Metal contents in the residues of the ZPR-Co process.

\begin{tabular}{cccc}
\hline \multirow{2}{*}{$\begin{array}{c}\text { Residues from the } \\
\text { ZPR-Co Process }\end{array}$} & \multicolumn{3}{c}{ Content $(\mathbf{m g} / \mathbf{L}$ or \%) } \\
\cline { 2 - 4 } & $\mathbf{Z n}$ & $\mathbf{C d}$ & $\mathbf{C u}$ \\
\hline Soln from washing $(\mathrm{mg} / \mathrm{L})$ & 1202 & 3067 & 3.6 \\
Soln from Co ppt $(\mathrm{mg} / \mathrm{L})$ & 1111 & 317 & 3028 \\
Leach solid residue (\%) & 2.06 & 0.22 & 36.4 \\
Fe-Mn solid residue (\%) & 2.09 & 0.13 & 1.97 \\
\hline
\end{tabular}

\section{Conclusions}

A process to obtain a cobalt rich hydroxide from the processing of a $\mathrm{Cu}-\mathrm{Cd}-\mathrm{Co}$ residue produced by cementation on zinc dust is described in this paper. The process includes a water leaching of the residue to remove soluble $\mathrm{Zn}$ and $\mathrm{Cd}$. The washed residue is leached for $30 \mathrm{~min}$ with sulfuric acid $(100 \mathrm{~g} / \mathrm{L})$ at a $\mathrm{pH}$ of 0.2 . The Fe and $\mathrm{Mn}$ of the leach solution are precipitated by increasing the Eh to $650 \mathrm{mV}$ while maintaining a $\mathrm{pH}$ of 3.0 with sodium hydroxide. Cobalt hydroxide is finally precipitated by increasing the Eh to $1000 \mathrm{mV}$. Repetition of the whole processing flow sheet shows that the critical steps of the process are the control of the Eh at the precipitation stage and the solids/liquid filtration of the Fe-Mn precipitate. The cobalt recovery from the zinc residues to the cobalt hydroxide is $62 \pm 14 \%$. The cobalt content of the cobalt product is $45 \pm 4 \%$. The variability in the results is mainly due to the control and measurement of the solution Redox potential

Author Contributions: Conceptualization, investigation, formal analysis methodology, data curation, writing-review and editing, L.B.; conceptualization, investigation, formal analysis methodology, data curation, supervision, writing - review and editing, K.T. and J.-F.B.; writing-original draft preparation, writing-review and editing, formal analysis, supervision, project administration, C.B.; funding acquisition, conceptualization, review, G.H. All authors have read and agreed to the published version of the manuscript.

Funding: This research was funded by Institut de recherche de Hydro-Québec.

Acknowledgments: The authors acknowledge the financial support of the Institut de recherche de Hydro-Québec and CEZinc for providing the zinc residues sample for the testwork. E. Benguerel, of CEZinc, is also acknowledged for reviewing the paper prior to publication.

Conflicts of Interest: The authors declare no conflict of interest.

\section{References}

1. Huang, Y.; Zhang, Z.; Cao, Y.; Han, G.; Peng, W.; Zhu, X.; Zhang, T.-A.; Dou, Z. Overview of cobalt resources and comprehensive analysis of cobalt recovery from zinc plant purification residue-a review. Hydrometallurgy 2020, 193, 3-12. [CrossRef]

2. Wang, Y.; Zhou, C. Hydrometallurgical process for recovery of cobalt from zinc plant residue. Hydrometallurgy 2002, 63, 225-234. [CrossRef] 
3. Fattahi, A.; Rashchi, F.; Abkhoshk, E. Reductive leaching of zinc, cobalt and manganese from zinc plant residue. Hydrometallurgy 2016, 161, 185-192. [CrossRef]

4. Anonymous. Critical Materials Rare Earths Supply Chain: A Situational White Paper; U.S. Department of Energy, Office of Energy Efficiency \& Renewable Energy: Washington, DC, USA, 2020.

5. Golmohammadzadeh, R.; Faraji, F.; Rashchi, F. Recovery of lithium and cobalt from spent lithium ion batteries (LIBs) using organic acids as leaching reagents: A review. Resour. Conserv. Recycl. 2018, 136, 418-435. [CrossRef]

6. Frankel, T.C. The Cobalt Pipeline: Tracing the Path from Deadly Hand-Dug Mines in Congo to Consumer's Phones and Laptops. The Washington Post, 1 October 2016. Available online: https://longform.org/posts/thecobalt-pipeline (accessed on 3 November 2020).

7. Ashtari, P.; Pourghahramani, P. Hydrometallurgical recycling of cobalt from zinc plants residue. J. Mater. Cycles Waste Manag. 2018, 20, 155-166. [CrossRef]

8. Güler, E.; Seyrankaya, A. Precipitation of impurity ions from zinc leach solutions with high iron contents-A special emphasis on cobalt precipitation. Hydrometallurgy 2016, 164, 118-124. [CrossRef]

9. Bøckman, O.; Østvold, T. Products formed during cobalt cementation on zinc in zinc sulfate electrolytes. Hydrometallurgy 2000, 54, 65-78. [CrossRef]

10. Qian, L.; Zhang, B.; Min, X.-B.; Shen, W.-Q. Acid leaching kinetics of zinc plant purification residue. Trans. Nonferrous Met. Soc. China 2013, 23, 2786-2791.

11. CEzince Company. Available online: https://www.cezinc.com/fr/Pages/home.aspx (accessed on 5 August 2020).

12. Gy, P.M. Sampling of Particulate Materials, Theory and Practice; Elsevier: Amsterdam, The Netherlands, 1982.

13. Bazin, C.; Hodouin, D.; Zouadi, M. Data reconciliation and equilibrium constant estimation: Application to copper solvent extraction. Hydrometallurgy 2005, 80, 43-53. [CrossRef]

14. Hodouin, D.; Everell, M. A hierarchical procedure for adjustment and material balancing of mineral processes data. Int. J. Miner. Process. 1980, 7, 91-116. [CrossRef]

15. Hodouin, D.; Flament, F.; Bazin, C. Reliability of material balance calculations a sensitivity approach. Miner. Eng. 1989, 2, 157-169. [CrossRef]

16. Turgeon, K.; Bazin, C.; Boulanger, J.-F.; Whitty-Léveillé, L.; Larivière, D. Material balancing and estimation of equilibrium constants: Application to solvent extraction tests of rare earth elements. In Proceedings of the International Mineral Processing Congress, Quebec, QC, Canada, 11-15 September 2016.

17. Bazin, C.; Hodouin, D.; Blondin, R.M. Estimation of the variance of the fundamental error associated to the sampling of low grade ores. Int. J. Miner. Process. 2013, 124, 117-123. [CrossRef]

18. Zhan, D.; Marquez, J. First Cobalt Corporation: 2019 First Cobalt Refinery Restart. 103870-RPT-0001. Available online: https://www.firstcobalt.com/_resources/reports/20190627-Ausenco-ConceptualStudy_Rev-E. pdf (accessed on 20 November 2020).

19. Box, G.E.; Draper, N.R. Evolutionary Operation: A Statistical Method for Process Improvement; Wiley: New York, NY, USA, 1969; Volume 25.

20. Conard, B. History of electrolytic cobalt refining at Vale Canada (Inco). CIM J. 2015, 6, 51-58. [CrossRef]

Publisher's Note: MDPI stays neutral with regard to jurisdictional claims in published maps and institutional affiliations.

(C) 2020 by the authors. Licensee MDPI, Basel, Switzerland. This article is an open access article distributed under the terms and conditions of the Creative Commons Attribution (CC BY) license (http://creativecommons.org/licenses/by/4.0/). 